Magda Heydel Uniwersytet Jagielloński*

\title{
Rób swoje, tłumacz! Przekładoznawstwo jako metoda w humanistyce
}

Do your job, translate! Translation Studies as a method in the humanities

\begin{abstract}
Translation has become one of the most important aspects of contemporary culture in the globalised world: it is a condition for intercultural communication as well as a means of preservation of culturally specific elements. No longer can we ignore the impact is has on cultural praxis and the functioning of many disciplines of the humanities. As a methodological framework Translation Studies offers a set of analytic and interpretive tools for research into various "translation zones", for a long time seen as marginal, but in fact the most active spaces in cultures. It is there that the mediation processes and cultural transfer happens. The paper looks at the ways in which Translation Studies defines its aims and methods and sketches possible uses they may be put into in the humanities. The Translational Turn in Culture Studies poses challenges both to TS and other disciplines of the humanities, at the same time offering promising, new research perspectives.
\end{abstract}


* Wydział Polonistyki Uniwersytetu Jagiellońskiego ul. Gołębia 16, 30-001 Kraków e-mail: m.heydel@uj.edu.pl 
Zacznę od sceny z dramatu Translations (1981) pióra Briana Friela, klasyka irlandzkiego teatru XX wieku. Rzecz dzieje się w małej wioseczce w hrabstwie Donegal, w roku 1833, a więc w okresie, kiedy Irlandia jest angielską kolonią. Brytyjczycy wprowadzają właśnie dwie reformy: szkolnictwa na poziomie podstawowym, przekształcając tzw. hedge schools w szkoły państwowe, oraz topograficzno-onomastyczna, sporządzając nowe mapy Irlandii. W wiosce pojawiają się angielscy wojskowi ze służb kartograficznych, którzy mają za zadanie dokonanie pomiarów i przeredagowanie miejscowych map, tak by zastapić nazwy gaelickie angielskimi. Ponieważ ludność nie posługuje się językiem angielskim, oficerowie wynajmują thumacza — jednego z synów miejscowego nauczyciela, który na skutek reformy traci posadę. Wielowątkowa akcja dramatu rozwija się nie bez zabawnych incydentów i nieporozumień — jeden z Anglików zakochuje się oczywiście w Irlandce - niemniej ostatni akt ma wymowę pesymistyczną, mroczną, omalże tragiczną. Kiedy zakochany oficer gdzieś przepada, Anglicy grożą mieszkańcom wioski represjami, łącznie z wybiciem trzody, wysiedleniem ludności i zrównaniem domostw z ziemią. Wstrzaśnięty tłumacz, który nagle odkrywa, że znalazł się w sytuacji bez wyjścia, zamiast przekazać hiobowe wieści ziomkom, na groźbę reaguje słowami: You are not--! / „Nie zrobicie tego!”; na co otrzymuje zimną odpowiedź: Do your job, translate! / „Rób swoje! Tłumacz!” (Friel 2000: 80)².

Ta wymowna scena ze sztuki, której zasadniczym tematem jest niemożność porozumienia, różnice językowe oraz wpływ przemocy jednego języka wobec drugiego na życie pojedynczych ludzi i całej społeczności, jak w soczewce skupia zagadnienia znajdujące się dziś w centrum refleksji przekładoznawczej i towarzyszące refleksji nad tym, czym jest tłumaczenie, jakie są warunki jego istnienia i funkcjonowania, do czego służy, komu służy oraz, last but definitely not least, kto, dlaczego, jak, w jakim celu i na jakich warunkach jest jego podmiotem. Zadając takie pytania, przekładoznawstwo wychodzi z impasu, w jakim znalazło się po radykalnym przyjęciu lekcji językoznawstwa i wiary w zasadę ekwiwalencji. Pisał o tym George Steiner, stwierdzając, że wina teorii tłumaczenia polega na tym, iż rozwija się ,jak gdyby” (as if) kwestie relacji między oryginałem a przekładem zostały rozwiązane albo jakby ich rozwiązanie były wynikiem samego aktu przekładu. „Praxis (...) musi przyjmować postawę jak gdyby — pisze Steiner — teoria nie ma do tego prawa"

1 Polskie wersje cytatów w moim niepublikowanym przekładzie. 
(Steiner 2000: 382). Nowe przekładoznawstwo odmawia działania ,jak gdyby”, dopytuje o warunki i konteksty zrozumienia problemów relacji w przekładzie i nie zgadza się na przechodzenie do porządku dziennego nad aporiami.

Owen, tłumacz ze sztuki Friela, dokonuje przekładu niedokładnie, na różne sposoby i z różnych przyczyn manipulując nie tylko treścią angielskich komunikatów, ale także ich rejestrem i wartością retoryczna. Jego dezynwoltura z jednej strony ujawnia głęboka pogardę dla przybyszów, którzy wprawdzie go zatrudnili, ale nie zasługują na poważne traktowanie, $z$ drugiej także pewien dystans wobec współziomków, których prowincjonalność nagle rzuca mu się w oczy z całą jaskrawością. Od razu jednak jest jasne, że to nie kwestie czysto językowe są tu zasadniczą płaszczyzną działania. Nie chodzi o językowo pojętą wierność przekazywanego przez tłumacza komunikatu, ale o to, co w tym kontekście komunikaty te rzeczywiście znaczą. Konstatacja, że przekład jest niedokładny, bo nie odtwarza struktur syntaktycznych i leksykalnych tekstu wyjściowego jest tu nieistotna, zwłaszcza że treści wyrażane przez brytyjskich oficerów, przede wszystkim ostateczna groźba, jednak do miejscowych docierają.

Przekład, w prostym sensie transferu, nawet jeśli jest skuteczny funkcjonalnie, zawsze okazuje się niedokładny, nie w pełni ekwiwalentny — gdyby był absolutnie ekwiwalentny, przestałby być przekładem (Hermans 2015: 36), a zatem zawsze przynosi ze sobą cały szereg konsekwencji wykraczających poza obszar językowej odpowiedniości. W scenie z dramatu Friela w grę wchodzi imperialna polityka, konflikt, kwestia lojalności, przynależności do wspólnoty, sprawa tożsamości jednostkowej i zbiorowej, a wreszcie zagrożenia dla mienia i życia ludzi. Uznawana za prostą, oczywistą i niewymagającą głębszego przemyślenia czynność, którą wykonuje lub ma wykonywać tłumacz — także tego, co mu wolno, a czego nie — okazuje się co najmniej problematyczna. „Rób swoje, tłumacz!” — Do your job, translate - to w zasadzie zadanie niewykonalne, choć niby niebudzące wattpliwości ${ }^{2}$.

Swoje uwagi chciałabym skoncentrować na współczesnych nieekwiwalentystycznych i niejęzykoznawczych ujęciach przekładu w jego różnych aspektach, stawiając tezę, że jeśli mamy mówić o humanistyce jako translacji oraz dostrzec wartość myśli przekładoznawczej jako metody w dzisiejszej humanistyce, musimy przy definiowaniu przekładu i wyprowadzaniu z niego narzędzi badawczych czy metodologicznych, posługiwać się kategoriami wypracowanymi właśnie w ramach nowoczesnych Translation Studies. A to oznacza przesunięcie akcentów i konieczność redefinicji podstawowych kategorii dyscypliny (Bassnett 2014; Pym 2010; Heydel 2010: 23). Przedstawię zatem najpierw krótko zmiany w przekładoznawstwie ostatnich lat, a następnie naszkicuję wybrane wyzwania, jakie stawia tej dyscyplinie paradygmat badań humanistycznych, który także ulega dzisiaj przemianom i redefinicjom, a więc o potencjalnych sposobach użycia kategorii wypracowanych w obszarze przekładoznawstwa w badaniach szeroko pojętej nowej humanistyki.

2 Polszczyzna daje nam tu prezent, a mianowicie słówko „swoje”. Czym jest owo „swoje” tłumacza? Gdzie jest jego swojość? Gdzie i czyj jest tłumacz? W ujęciach teoretyzujących przekład jako zagadnienie językowe, tłumacz to figura w zasadzie niewidoczna (taki jest ideał w koncepcjach ekwiwalencji), a w najlepszym razie mająca charakter abstrakcyjnego tworu, instancji pośredniczącej w wymianie międzyjęzykowej. Nowsze przekładoznawstwo proponuje takie spojrzenie na tłumacza, które nadaje mu centralną pozycję. 
W połowie lat 80. ubiegłego wieku rozpoczą się proces zmian w obszarze studiów nad przekładem, które zresztą jako oddzielna dyscyplina ukonstytuowały się w humanistyce zachodniej niewiele wcześniej, bo w początku lat 70., wyodrębniając się z obszaru językoznawstwa z jednej a literaturoznawstwa porównawczego z drugiej strony (Holmes 2007; Hermans 1985). W Europie Środkowej i Wschodniej sytuacja wyglądała nieco inaczej, jako że istniała tu silna tradycja strukturalistyczna związaną z badaniami nad językiem artystycznym, a więc proponującą swoje poetyki i stylistyki, która jest zresztą do dziś wpływowa (Gierowski 2013). Najogólniej i sumarycznie rzecz ujmując, proces określany mianem Cultural Turn in Translation Studies, który nabrał impetu w latach dziewięćdziesiątych XX wieku, polegał na znacznym poszerzeniu obszaru badań przekładowych i przesunięciu ich z domeny transferu międzyjęzykowego czy międzytekstowego, a więc tego, co Roman Jakobson nazwał „przekładem właściwym” (Jakobson 2009), na obszar badań nad stykami kultur czy światów kulturowych, na dynamikę tych relacji, towarzyszące jej napięcia i tarcia (Snell-Hornby 2006: 164-9; Bassnett 2014: 16-36, 168-178).

Proces ten mial swoje konsekwencje na poziomie metodologii badawczej, a przede wszystkim spowodował zmianę zasadniczych kategorii opisujących zjawisko podlegające opisowi. Najistotniejsze elementy owej zmiany zebrać można w następujących formułach:

- przeniesienie ogniskowej z domeny wyjściowej na domenę docelową (target-oriented approaches); zarówno synchronicznie, jak i diachronicznie; w centrum badań nad przekładem staje nie oryginał, ale tłumaczenie i warunki, w jakich funkcjonuje;

- $\quad$ przesunięcia w obrębie zasadniczych kategorii: pojęcia oryginału, odpowiedniości czy wierności traca centralne miejsce w dyskursie przekładoznawczym; relacja ekwiwalencji podlega problematyzacji, której radykalnym efektem jest uznanie jej za „użyteczna fikcję społeczną", czyli strukturę wiary (por. m.in. Pym 2010: 37-38; Hermans 2015: 9-36);

- pojawienie się nowych kategorii, takich jak funkcja przekładu, reprezentacja, transformacja/manipulacja, przepisanie, przeniesienie, inność, różnica kulturowa, relacja władzy; tym samym uwaga badaczy kieruje się ku społecznym warunkom przebiegu aktu przekładu, a nie jego językowemu zakotwiczeniu oraz stylistycznej wartościom (por. m.in. Hermans 1985; Lefevere 1992);

- otwarcie nowych interdyscyplinarnych obszarów: socjologii przekładu (Wolf, Fukari 2007), historii przekładu (Pym 1998; Venuti 1995), nowej komparatystyki (Bassnett 1993; Apter 2006a; Bilczewski 2010), antropologii przekładu (Geertz 1973; Brocki 2008);

- włączenie w namysł nad przekładem refleksji nad niestabilnością i niezdeterminowaniem znaczenia, a co za tym idzie zagadnień poststrukturalistycznej filozofii języka (Pym 2010: 90-113; Venuti 2013) oraz nowoczesnej hermeneutyki (Steiner 2004; Ricoeur 2006);

- poddanie krytyce kategorii aksjologicznych i mechanizmów służących ocenianiu tłumaczenia (tertium comparationis, inwariant, reprodukcja znaczeń) oraz normatywnego wymiaru teorii; punktem wyjścia dla badań staje się paradygmat deskryptywny (Toury 1995); krytyka przekładu zajmuje w związku z tym oddzielne miejsce, bliższe krytyce 
literackiej; sama zatem także staje się przedmiotem badania dla przekładoznawstwa, pozwalając na wyciąganie wniosków co do zmiennych w czasie i zależnych od wielu czynników kryteriów opisu zjawiska przekładu.

Dzięki zwrotowi kulturowemu i związanym z nim zmianom Translation Studies stawiaja obecnie pytania, których zakres i znaczenie wychodzi daleko poza lokalne i ograniczone zagadnienia opisu oraz oceny (zwłaszcza oceny) konkretnych przypadków. Przekład rozumiany jako konkretny twór tekstowy nie jest już obiektem badawczym samym w sobie, ale punktem wyjścia do analizy szerszych zjawisk, symptomem pewnych procesów wewnątrzkulturowych i międzykulturowych.

W wyniku takiego otwarcia pola, relacje przekładowe w skali mikro zyskuja szeroki kontekst w skali makro: pojedyncze zjawisko przekładowe funkcjonujące na niskim poziomie uogólnienia, np. pojedynczy wiersz w przekładzie, jest już nie tylko samoistnym obiektem analizy poetyckiej, stylistycznej czy historycznoliterackiej, wydzielonym elementem gry w polu literackim, ale staje się symptomem pewnych cech czy funkcji większych całości, takich jak polisystem literacki lub kulturowy, widzianych zarówno synchronicznie, jak i diachronicznie (Bassnett, Lefevere 1998). Oznacza to także, że wielkie obszary problemowe można postrzegać jako konglomeraty mikroobiektów, w tym przekładowych, które poddają się krytycznej analizie także na mikropoziomie. A to z kolei oznacza, że przekłady postrzega się jako elementy szerszego pola relacji władzy i zależności, przynależne do takich wielkich międzykulturowych procesów, jak kolonizacja czy globalizacja.

Nic dziwnego, że takiemu poszerzaniu obszaru badawczego przekładoznawstwa, a więc i daleko idącej redefinicji przekładu, towarzyszą obawy co do trwałości samego pojęcia (Trivedi 2012; Dizdar 2009). Co dziś oznacza termin „przekład”? Jeśli stosowany jest w tak licznych i szerokich kontekstach, może — zastanawiają się niektórzy badacze utracić znaczenie, wytrzeć się, jak przekazywana z rąk do rąk moneta, której nominału już nie da się odczytać.

Harish Trivedi stwierdza na przykład, że pojęcie przekładu kulturowego, cultural translation, proponowane przez Homiego Bhabhę w odniesieniu do prozy Salmana Rushdiego, nie ma nic wspólnego z przekładem jako takim. Badacz broni przekładu rozumianego jako taki proces, którego sine qua non stanowi para tekstów oraz stworzona między nimi przez tłumacza relacja, przed rozmyciem w morzu metaforycznych, zwłaszcza niefachowych i niepoddanych teoretycznemu rygorowi, użyć i zastosowań tego słowa. Trivedi sugeruje wręcz, że może najwyższa pora, by wszyscy „dobrzy mężczyźni, a i, prawda, kobiety, którzy parali się kiedykolwiek przekładem” zjednoczyli się i zastrzegli ten termin dla szlachetnej czynności, której się oddają. Jeśli jeszcze nie jest za późno, dodaje (Trivedi 2012).

Obawa przed metaforycznym używaniem terminu „przekład” oraz dystans wobec takich użyć pojawiają się często w okołoprzekładowych dyskusjach i eseistyce (por. Lukasiewicz 2017). Czym innym jednak jest metafora rozumiana jako ozdobny czy niebanalny sposób ujęcia praktyki tłumaczeniowej, nierzadko zresztą oświetlający jej nieoczywiste aspekty, czym innym natomiast poszukiwanie nowego rozumienia samego pojęcia. Będę starała się pokazać, że postawy nieufności wynikają nierzadko z błędnego, bo przestarzałego i zbyt wąskiego rozumienia samego pojęcia przekładu, a zatem i możliwości posłużenia się nim jako matrycą badawczą w humanistyce. Z drugiej jednak strony, opuszczając bezpieczne pole paradygmatu ekwiwalencyjnego, gdzie przekład oznaczał ruch od tekstu 
wyjściowego do docelowego z zachowaniem pewnych uprzednio zdefiniowanych wartości (Nida 1959), mamy do czynienia z bardziej skomplikowanymi wzorcami, nie tak łatwo poddającymi się schematyzacji, a więc trudniejszymi w użyciu. Rosemary Arrojo pisze a ja chętnie podtrzymuję jej zdanie — że nie wolno zniechęcać się złożonym charakterem przekładu i skomplikowaniem jego działania, inaczej grozi nam powrót „dawnych klisz, które pomniejszają wpływ tłumaczy na kształt historii i kultury” (2002: 78).

Podobnie jak w przypadku wielu innych pojęć definicje zamykające i ograniczające pękaja pod naporem faktów dostarczanych przez studia opisowe. Przekład to termin obejmujący tak wiele różnorodnych zjawisk i mający tak wiele różnorodnych aspektów, że klasyczna definicja, ostro oddzielająca go od innych form komunikacji międzykulturowej, nie może satysfakcjonować (Lefevere 1992). Maria Tymoczko na przykład postuluje, by definicję pojęcia *przekład (*translation) budować w oparciu o Wittgensteinowską kategorię podobieństwa rodzinnego lub sieciową kategorię radialną z centralnym relatywnym elementem prototypowym. W ten sposób otwiera granice definicji i dopuszcza możliwość powstawania alternatywnych węzłów czy krystalizacji znaczeń w jej ramach, zamiast odgradzać przekład od zjawisk, które zostaną uznane za już do tej kategorii nienależące (Tymoczko 2007: 83 i n.).

Pomimo takiej otwartej struktury definicyjnej w definicji pojęcia przekładu zawsze pozostaje element napięcia i rozciągający się między wchodzącymi w relację domenami obszar „pomiędzy” (in-between), który za Emily Apter określa się często jako strefę przekładu, translation zone (Apter 2006a; Heydel 2013: 81-84). To w niej działa tłumacz, w niej następują procesy, które w istocie mają strukturę znacznie bardziej skomplikowaną i wieloaspektową niż chcieliby wyznawcy wizji przekładu jako odwzorowywania czy przenoszenia znaczeń ${ }^{3}$. Przekładoznawstwo stawia pytania nie tylko o rezultat tekstowy (i jego fortunność), ale również o społeczne, polityczne, ideowe czy etyczne uwarunkowania i konsekwencje owych procesów. Wiemy już, że przekład to wielowarstwowy, złożony klaster pojęciowy (Tymoczko 2007: 83 i n.), nie maszyna do tworzenia tożsamości, ale generator różnicy, hybrydyczności i niejednoznaczności (Dizdar 2009). Jego podstawowymi aspektami są nie powtórzenie i odwzorowanie, ale różnica i hybrydyzacja.

Rosemary Arrojo, której myśl wyrasta z inspiracji modernistyczną brazylijską koncepcją przekładu „kanibalistycznego” (Bassnett i Trivedi 1999: 15-17; Vieira 1999: 59-113; Snell-Hornby 2006: 60-63; Borowski 2012), posługuje się metafora palimpsestu, aby zanegować wizję tłumaczenia jako przemieszczania znaczeń niczym przewożonego wagonami towaru, proponując w zamian inną ramę metaforyczno-konceptualną, a mianowicie palimpsest. Palimpsest to tekst nadpisany na istniejącym uprzednio tekście. Aby mógł zaistnieć, musi nastapić fizyczne wymazanie owego zapisu, dzięki czemu powstaje miejsce dla nowego (Arrojo 1986, 24). Obraz palimpsestu przywołuje wymiar czasowy procesu translacji, podkreślając, że mowa o zjawisku diachronicznym, uwikłanym w okoliczności swej epoki. Uwypuklony zostaje także fizyczny aspekt tłumaczenia jako obiektu oraz procesu pracy tłumacza. Warto zwrócić uwage i na to, że metafora palimpsestu uaktywnia

3 Dzisiejsze rozumienie przekładu nie pozwala sprowadzać jego „właściwej” postaci do zagadnienia międzyjęzykowej reprezentacji o tak czy inaczej określonym poziomie fortunności, a więc na przykład posługując się metafora portretu. Zdajemy sobie sprawę, że siedzący bez ruchu model jest wyizolowanym, sztucznym obiektem, wyłączonym ze swojego normalnego życia, które wszak polega na ruchu (więc jeśli już, to będzie to portret dynamiczny, w ruchu, modernistyczny). 
element agoniczny w przekładzie: wersje zapisu nie współistnieją, lecz późniejsza (tłumaczenie) wypiera wcześniejszą (oryginał), choć ślady istnienia poprzedniego pisma zawsze będą do pewnego stopnia przebijać spoza nadpisanego tekstu. Translacja-palimpsest okazuje się zatem również przestrzenią zmagania, translation zone, w której panują nie pokój i harmonia, ale walka.

Pokrewną wizję przekładu jako zmagania proponuje wychodzący z poststrukturalistycznych koncepcji języka i kultury Lawrence Venuti. Szkicując w różnych tekstach swoją (wciąż jeszcze chyba nie mającą ostatecznego kształtu) koncepcję hermeneutycznego modelu przekładu jako aktu interpretacyjnego, wynikłą m.in. z inspiracji myślą Derridy i Lecercle'a, Antoine’a Bermana, a także Alana Badiou (Venuti 2013), amerykański badacz występuje przeciwko instrumentalizmowi w postrzeganiu przekładu, a więc tym jego koncepcjom, które przypisują mu rolę służebną w reprodukowaniu inwariantu. Venuti podważa istnienie inwariantu tłumaczeniowego, w zamian proponuje natomiast takie ujęcie, które istotę przekładu widzi w nadpisaniu czy inskrypcji znaczeń, jakiej dokonuje tłumacz; tłumacz z kolei jest powiązany siecią zależności z własnym czasem i kulturą oraz językiem jako nośnikiem istniejących w niej dynamicznie interesów i konfliktów (Venuti 2009: 267293; Heydel 2013: 72-79). W ten sposób, jak przekonująco pokazują precyzyjne i szczegółowe analizy Venutiego, do przekładoznawstwa wprowadzić można (w pewnym sensie: na powrót) historyczność, tekstualność i podmiotowość, a narzędzia tej dyscypliny okazuja się przydatne w badaniach humanistycznych, bowiem dotykają istotnych wątków kultury.

Aby skutecznie i z pożytkiem posłużyć się przekładem jako metodologią humanistyki, trzeba zatem dokonać redefinicji jego najistotniejszych aspektów, a także wskazać obszary refleksji humanistycznej, w których mogą się one okazać funkcjonalne. Nie wystarczy proklamować rozwód przekładoznawstwa z językoznawstwem ${ }^{4}$ i wprowadzać w zamian kategorie pochodzące $z$ innych dziedzin humanistyki (np. socjologii czy studiów postkolonialnych). Chodzi raczej o przeniesienie kategorii przekładu w jej istotnych wymiarach wyprowadzonych z nowoczesnego, złożonego modelu funkcjonowania translacji (a więc np. transfer, mediacja, różnica, reinterpretacja, przekształcenie, kontakt, konflikt) w obręb innych dyscyplin i pól dyskursywnych humanistyki, aby wypróbować w nich skuteczność analityczną narzędzi przekładoznawczych, doskonaląc je zarazem dzięki zastosowaniu w nowych kontekstach (por. Bachmann-Medick 2012: 280-334).

Jednym z takich obszarów, który można lepiej zrozumieć dzięki zastosowaniu kategorii przekładowych, jest polityka językowa — wątek ten pojawia się właśnie w dramacie Briana Friela. Asymetrie językowe mają charakter relacji przemocowych. Różnorodne moga być ich bezpośrednie przyczyny i okoliczności, niemniej przekład staje się w ich ramach wymogiem ${ }^{5}$, który dotyka ludzkiej egzystencji na poziomie jednostkowym i wspólnotowym. Użytkownik języka mniejszościowego (u Friela jest to gaelicki) albo imigrant, przy pomocy sankcji politycznych czy ekonomicznych, zostaje przez instytucje dzierżące władzę zmuszony do podjęcia procesu autotranslacji. Dosłownie i niemetaforycznie musi przepisać swoje życie na inny język (por. Hoffman 1990). Może to być język etniczny hegemona,

4 Rozwód ten zresztą bynajmniej nie nastąił. Narzędzia i metody lingwistyczne są szeroko stosowane w kształceniu tłumaczy, tworzeniu różnorodnych narzędzi translatorskich czy rozwiązywaniu wielorakich problemów dotyczących tekstów technicznych, prawnych i w innych obszarach tłumaczenia pragmatycznego.

5 Co ciekawe, Vinay i Darbelnet (1957) właśnie w kontekście polityki językowej i zmagań o dominację w tym zakresie sformułowali swoja pionierską poetykę tłumaczenia. 
ale także język dominującej religii czy ideologii, wywierający presję na poddanych sobie ludzi. Historia dostarcza licznych przykładów tego rodzaju sytuacji, a sposoby ich rozstrzygania są istotnym wskaźnikiem rozgrywających się procesów kulturowych ${ }^{6}$. Kategorie przekładowe mogą w tym kontekście pomóc w zrozumieniu praktyki społecznej łączącej się z tymi zjawiskami, a także nowych form wielojęzycznej kultury, które mają strukturę palimpsestową. Ślady takich fascynujących zjawisk można odnaleźć nie tylko w zapisach socjologicznych, ale także w praktykach artystycznych w zakresie sztuk wizualnych ${ }^{7}$ oraz w dziełach literackich.

Przykładem dzieła wpisującego się w ów paradygmat działań w translation zone, tym ciekawszym, że wkracza bezpośrednio w przestrzeń polityczno-lingwistycznego sporu, dążąc jednak nie do osiagnięcia przewagi w zwarciu, ale do wyświetlenia i przemyślenia skomplikowanej, wielowarstwowej struktury, jest tłumaczenie staroangielskiego eposu Beowulf pióra irlandzkiego noblisty, Seamusa Heaneya (1999). W swojej wersji owego fundamentu literatury angielskiej, a więc — z irlandzkiej perspektywy — literatury najeźdźców i okupantów, Heaney proponuje potoczysty, jasny, a zarazem mięsisty i gęsty tekst, bez naiwnej czy sztucznej archaizacji lub podwyższania rejestru. Tłumaczy z języka anglo-saksońskiego na współczesną angielszczyznę, która ma jednak wyraźne hiberno-angielskie zabarwienie: dla poety, o czym sam pisze we wstępie do tłumaczenia, rewelacyjnym doświadczeniem bliskości archaicznego świata eposu oraz swoistą licencją na wprowadzenie w przekładzie własnego języka było odkrycie, którego dokonał jeszcze jako początkujący student anglistyki. Otóż niektóre staroangielskie słowa są w istocie nadal używane w irlandzkiej odmianie angielszczyzny jako codzienne wyrażenia, a znane mu od małego i kojarzone z rodzinnym domem wyrazy mają ten sam źródłosłów, co słowa wczesnośredniowiecznego poematu (Heaney 1999: XXII-XXX).

Wprowadzając je pół wieku później do swojego przekładu, poeta dokonuje więc swoistego przejęcia eposu przez prowincjonalną angielszczyznę irlandzką, udowadnia bowiem istnienie odległego pokrewieństwa, które z jednej strony nobilituje wiejską mowę najstarszej brytyjskiej kolonii, z drugiej natomiast rozszczelnia imperialne centrum, ukazując jego wewnętrzną niejednorodność i podważając jego czystość. Szczycący się osadzeniem w irlandzkiej angielszczyźnie przekład utworu, który należy do twardego jądra kultury najeźdźcy i do kanonu jej literatury, ma wymiar poetycki, ale także polityczny. To przecież nie tylko nowa, dobrze się czytająca angielska wersja starodawnego eposu, ale także gest wyrażający siłę irlandzkiej literatury, jej emancypację, odzyskaną moc kolonii, która może teraz na własnych warunkach przepisywać kulturę imperialnego najeźdźcy, by ukazać metropolii nowe oblicze pozornie dobrze jej znanego dzieła. Umieszczanie irlandzkich słów w staroangielskim

$6 \quad$ Wyrazistym i zbyt mało jeszcze pod tym względem zbadanym obszarem jest kultura polska XIX wieku, z jednej strony poddana presji języków zaborców, z drugiej — koncentrująca się intensywnie na zachowaniu polszczyzny jako centrum tożsamości narodowej i kulturowej. Interesującego materiału dostarczyć może także okres drugiej wojny światowej i zjawiska językowe powstałe na różnych obszarach styku z językiem okupanta, którego najdramatyczniejszym być może przykładem byłaby Lagersprache (por. Tryuk 2011; Glowacka 2014; Kuhiwczak 2015). Z drugiej strony mamy także badania nad bi- i plurilingwizmem obszarów postkolonialnych (...) oraz wielkomiejskich środowisk epoki globalizacji (Simon 2006).

7 Myślę tu o takich przedsięwzięciach jak projekty lingwistyczne grupy Slavs and Tatars, zwłaszcza ich wystawa „usta usta”. Por. strony WWW Slavs and Tatars oraz Centrum Sztuki Współczesnej Zamek Ujazdowski. Innym przykładem jest polsko-niemiecki projekt fotograficzno-tekstowy $A-Z$. Stownik ilustrowany jesylka polskiego i niemieckiego Andrzeja Tobisa z 2014 roku. 
eposie, pisze Heaney, ,zdało mi się sposobem, w jaki irlandzki poeta może poradzić sobie ze złożoną historią najazdu i kolonizacji, nasiąkania i oporu, uczciwości i antagonizmu, z historią, którą wszyscy zainteresowani muszą niewątpliwie przyjąć” (1999: XXX).

Widać tu jak na dłoni, że dwubiegunowe i skupione na „wierności” pojęcie przekładu nie może sprawdzić się jako narzędzie opisu tego rodzaju zjawisk. Gdyby o Beowulfie Heaneya powiedzieć, że jest „niewierny” albo że tłumacz „dodaje sporo ze swojego idiomu”, niewiele by nam to wyjaśniło. Celem tego przedsięwzięcia poetyckiego nie było odwzorowanie, stworzenie iluzorycznego lustrzanego odbicia pozornie jednoznacznego oryginału. Warto popatrzeć nań jako na studium procesów mających miejsce w przestrzeni „pomiędzy”, in-between, podlegającej nieustannym negocjacjom, wzajemnemu kształtowaniu, zmaganiu, przepływowi. Przekład dokonany przez irlandzkiego noblistę jest zarazem modelową realizacją, jak i wzorcem działania językowego i społecznego w translation zone.

Innym przykładem obszaru wiele zawdzięczającego kategoriom przekładoznawczym są tzw. urban studies - studia nad miastem (Simon 2006), które stawiają sobie za cel m.in. opisanie procesu wzajemnego przenikania i strefy kontaktu międzykulturowego i międzyjęzykowego we współczesnych metropoliach, a co za tym idzie, badają struktury multikulturowości i diagnozuja jej problemy. Przy analizie nowoczesnej metropolii pojawia się także interesujący wymiar kognitywno-psychologiczny w kontekście bilingwizmu i multilingwizmu. Wyrazistym przekładem jest kwestia zmiany definicji i funkcjonowania pojęcia języka rodzimego czy pierwszego, a więc tego, który w przekładzie odpowiadałby pozycji oryginału. Badania nad multilingwalnymi obszarami wielkomiejskimi i migracja dostarczaja coraz bogatszego materiału podważającego istnienie takiej kategorii w jej dotychczasowym, stabilnym znaczeniu — redefiniując także do pewnego stopnia kwestię „przekładania siebie” (por. Hoffmann 1990). Osoby urodzone w wielojęzycznych środowiskach migracyjnych, często pochodzące z bi- lub polilingwalnych społeczeństw, dodatkowo jeszcze wystawione na procesy wzmacniające rozszczepienie tożsamości językowej poprzez funkcjonowanie w wielu różnych sferach językowych — innej w domu, innej w szkole — nie sa już w stanie opisywać siebie ani być opisywane przy pomocy kategorii języka ojczystego i nabytego.

Ujawniona przez przekładoznawstwo nieciągłość relacji międzyjęzykowej dostarcza narzędzi do nowego rozumienia zjawiska wielojęzyczności. A idąc dalej, pozwala także badać różne aspekty i poziomy relacji społecznych w środowiskach żyjących w strefie przekładu, na przykład rodziny, w których dzieci są tłumaczami dla swoich rodziców. Pojawiają się tu zagadnienia językowe, ale także z zakresu polityki, ekonomii, prawa, edukacji, psychologii czy medycyny itd. Poza szerokim polem zagadnień związanych z tożsamościa, konstrukcją jaźni itp., prowadzi to także do zmian w zakresie akwizycji językowej, a na płaszczyźnie nauk stosowanych stanowi wyzwanie dla twórców programów nauczania, podręczników i innych pomocy dydaktycznych do nauki języków.

Inny istotny obszar badawczy w erze globalizacji i migracji stanowią relacje między myśla zachodnią a niezachodnimi paradygmatami wytwarzania wiedzy, mogące prowadzić do podważenia pozycji europocentryzmu. Przekład jest w tym kontekście podstawowym narzędziem transmisji, a zarazem interpretacji. Ten obszar to wręcz modelowy przykład palimpsestowości translacji. Zachód ze swoim dążeniem do uniwersalizacji zasadniczo przekładał te wybrane elementy systemów niezachodnich, które uznawał za przydatne i inspirujące na tyle, by je wcielić w swój projekt. Zachodni model relacji przekładowej 
zakłada, że kolonie to tłumaczenia, oryginałem jest Europa (Bassnett i Trivedi 1999). Wiemy już jednak, że relacja przekładowa nie jest jednostronna, więc i europejski oryginał ulega w trakcie dziejów przekształceniom pod wpływem przekładowych kontaktów, chociaż - czego uczą postkolonialne studia nad przekładem — sztukę „dzikusów” trzeba było przełożyć na swoje kategorie, by móc ją wykorzystać (Bassnett i Trivedi 1999; Lefèvere 1992a: 80). Tłumacz stał w jednym szeregu z kolonizatorem — jak Anglicy u Friela, nadawał temu, co „odkrywał”, a więc uznawał za dotąd niegotowe, nieokreślone, wręcz nieistniejące, swoje własne nazwy, zamieniał na swoje formy, cywilizował. W rezultacie jednak powstawały hybrydy, twory charakterystyczne dla translation zone.

Obecnie możemy nie tylko badać te historyczne zjawiska czy ich dzisiejsze wcielenia, ale także analizować procesy przesuwania centrum i negowania europocentryzmu. Dipesh Chakrabarty w książce Provincionalizing Europe (2000), postuluje obok przekładu międzykulturowego także przekład międzykategorialny podważający pozycję zachodnich pojęć jako absolutnego punktu odniesienia dla rozumienia i porozumienia. Podobne tezy stawiają badaczki dyskursów i praktyk feministycznych w Azji, które negują uniwersalistyczne i absolutystyczne roszczenia zachodnich pojęć związanych z feminizmem (Spivak 2009; Devika 2008).

Taki sens terminu „przekład” wydobywa również Zygmunt Bauman, kiedy pisze:

Przekład międzykulturowy to nieustanny proces, który zarówno służy ko-habitacji ludzi, co stwarza ją tam, gdzie nie mogą oni pozwolić sobie ani na zajmowanie tej samej przestrzeni, ani też na mapowanie jej na własne, odmienne sposoby. Każdy akt przekładu ma wpływ na wzorce po obu stronach. Obie strony wychodzą z tego spotkania zmienione, na końcu owego procesu są inne, niż były na początku. (Bauman 2013)

Ta perspektywa, pozwalająca na dostrzeżenie sfer pomiędzy, obecnych w każdej kulturze na wielu poziomach, umożliwia większe zniuansowanie spojrzenia i poddanie krytyce koncepcji chcących widzieć kultury jako zunifikowane całości, dane, gotowe, stabilne. Nie są one już w istocie obiektami przekładu w sensie tradycyjnym, nie mają bowiem ustabilizowanych granic i struktur. Ukazują się natomiast jako dynamiczne układy współistniejących ze sobą postaw, wartości, języków, przestrzeniami ko-habitacji, konfliktów, różnic, praktyk hybrydyzujących. Mówiąc językiem Venutiego, mamy do czynienia z ruchliwą materią interesów i interpretacji, a każde ujęcie będzie aktem interpretacyjnym, jedną z wersji nadpisanych na poprzednich. Przekład nie jest tu jedynie poręczną metafora, lecz istota uchwyconych in flagranti relacji.

Historia kultur w tej perspektywie to dzieje stref przekładu, których wytwory moga być zarówno błogosławione, jak i przeklęte. W tym duchu pisze m.in. Judith Butler, która stwierdza, że kultura światowa to proces niekończącego się przekładu międzykulturowego (2002: 49-50). Również Homi Bhabha czy Emily Apter posługują się mocnymi, choć uogólniającymi hasłami „translational transnationalism” (Apter 2006b) czy „translation transnation" (Bhabha 1994). W moim przekonaniu zadaniem przekładoznawstwa dzisiaj jest krytyczne spojrzenie również na takie atrakcyjne aliteracyjnie i retorycznie formuły, by sprawdzić, czy nie stosuja metaforycznej przemocy, zamiast zaprząc do pracy przekładoznawcze kategorie. Podobnie jak termin „globalizacja” — sam stanowiący wdzięczny obiekt badań przekładoznawczych (Cronin 2003) — również „pan-translacja” niewiele wyjaśnia, a wiele zaciemnia. 
Jakie zatem są najskuteczniejsze i najostrzejsze krytycznie sposoby użycia kategorii przekładowych do analizy zjawisk humanistycznych? Kategorie te pozwalają uzyskać wgląd w procesy transferu pojęć, przebiegi reinterpretacji myśli humanistycznej, również pozaeuropejskiej (historię nauki również można badać w kontekście historii przekładu); pozwalają rozumieć złożoną genealogię dużych formacji kulturowych, takich jak kapitalizm czy modernizm oraz rozszczelniać złożone klastery pojęciowe takie jak kultura, tożsamość, tradycja, religia, ideologia. Jednakże koniecznym etapem w dochodzeniu do takich kuszących uogólnień są żmudne, nieraz szczegółowe badania nad poszczególnymi przypadkami, osadzonymi w konkretnych kontekstach i okolicznościach, z uwzględnieniem postaw i pozycji działających podmiotów, tak na płaszczyźnie synchronicznej, jak i diachronicznej. Epistemologiczny wymiar przekładu polegałby na skutecznym ujawnianiu nieciąłości tam, gdzie dotąd dostrzegaliśmy gładką powierzchnię. Przekładoznawstwo i jego narzędzia moga, krótko mówiąc, służyć do wyświetlania skomplikowanej struktury „wielkich narracji”, poddając je fragmentacji i wnikając w łączenia uznane na mocy społecznie akceptowanych ustaleń za trwałe.

Rodzi to oczywiście szereg pytań i wątpliwości. Niemniej, skoro, co już wiemy, nie można liczyć na oparcie w postaci trwałej, ciagłej i stabilnej ramy, która dawałaby nam komfort wiary w ekwiwalencję jako zasadę działania świata, warto uważnie i szczegółowo analizować układy kulturowe, warunki i okoliczności, w jakich istnieja przedmioty humanistycznego namysłu, jak również i własną pozycję jako badaczy. Perspektywa przekładoznawcza wyczula na obecność iluzji ciagłości tam, gdzie w istocie mamy do czynienia z różnica. Dlatego przekład jest niebezpieczny i podejrzany: może doprowadzić do niekontrolowanego wycieku znaczeń, które wyciec nie miały.

Teoretyczka kultury i kulturoznawstwa Doris Bachmann-Medick (2007, 2009) pisze o trzech fazach zwrotu przekładowego (translational turn) w naukach o kulturze. Pierwszą jest przekładoznawcze podejście w wielu dziedzinach badań humanistycznych (kilka z nich starałam się zarysować). Druga — zastosowanie takiego podejścia do badania podziałów i więzi międzydyscyplinarnych w humanistyce (czy nauce w ogóle) poprzez rezygnację z ujęć uniwersalistycznych i centralistycznych, a skupienie się na obrzeżach, strefach kontaktu, a więc uznanie przekładu za model i czynnik połączeń interdyscyplinarnych czy transdyscyplinarnych. Trzecia, najbardziej dla Bachmann-Medick interesująca, to projekt humanistyki jako Translation Studies, realizowany przez zaprzegnięcie „,charakterystycznej samorefleksyjności kategorii przekładowych do pomocy w pojmowaniu naszych własnych studiów nad analizą kultury jako zadania przekładowego" (Bachmann-Medick 2009: 12).

Widziane w ten sposób Kulturwissenschaften miałyby się podjąć przekładu pomiędzy różnymi, specyficznymi i lokalnymi kulturami wiedzy. Tym sposobem globalizacja badań kulturowych mogłaby, być może, uniknacc sytuacji, w której zdominują ją anglojęzyczne, unifikujące, zachodnie dyskursy wraz z zapisanymi w nich pojęciami, przekonaniami, perspektywami i nastawieniami. Ta wizja — niewolna od pewnej utopijności — prowadzi nas z powrotem do irlandzkiej wioseczki Baile Beag / Ballybeg w hrabstwie Dun Na Gall / Donegal i do nieszczęsnego tłumacza, który nagle odkrył, że wcale nie tak prosto jest „robić swoje”. To ten tłumacz znajduje się w samym centrum naszkicowanego tu pola problemowego - jako przedmiot badania przekładoznawców i kulturoznawców, ale także jako podmiot przekładowej i kulturowej praktyki. 


\section{Bibliografia}

Apter Emily (2006a), The Translation Zone. A New Comparative Literature, Princeton UP, Princeton-Oxford.

- (2006b), "Je ne crois pas beaucoup a la literature comparée". Universal Poetics and Postcolonial Compatriotism [w:] Comparative Literature in an Age of Globalisation, red. H. Saussy, John Hopkins UP, Baltimore.

Arrojo Rosemary (1986), Officina de traducão. A teoria na prática, Editoria Atica, Sao Paulo.

- (2002), Writing, Interpreting, and the Control of Meaning. Scenes from Kafka, Borges, and Kosztola'nyi [w:] Translation and Power, red. M. Tymoczko, E. Gentzler, University of Massachusetts Press, Amherst.

Bachmann-Medick Doris (2012), Translational Turn [w:] tejże, Cultural Turns. Nowe kierunki w naukach o kulturze, przeł. K. Krzemieniowa, Oficyna Naukowa, Warszawa.

Bassnett Susan (1993), Comparative Literature. A Critical Introduction, Wiley-Blackwell, Oxford.

- (2014), Translation, Routledge, London-New York.

Bassnett Susan, Lefèvere André (1998), Constructing Cultures, Multilingual Matters, Clevendon.

Bassnett Susan, Trivedi Harish (1999), Intruduction: of Colonies, Cannibals and Vernaculars [w:] Post-colonial Translation. Theory and Practice, red. S. Bassnett, H. Trivedi, Routledge, London-New York.

Bauman Zygmunt (2013), Kultura jako 'praxis', PWN, Warszawa.

Bhabha Homi (1994), The Location of Culture, Routledge, London-New York.

Bilczewski Tomasz (2010), Ekonomia i polityka komparatystyki [w:] Niewspótmierność. Perspek.tywy nowoczesnej komparatystyki. Antologia, red. T. Bilczewski, Wydawnictwo UJ, Kraków.

Borowski Gabriel (2012), Transkreacja: myśl przekłtadowa Haraldo de Camposa, „Przekładaniec. A Journal of Translation Studies" nr 26.

Brocki Marcin (2008), Antropologia. Literatura — dialog - przełkład, Wydawnictwo Katedry Etnologii i Antropologii Kulturowej Uniwersytetu Wrocławskiego, Wrocław.

Butler Judith (2002), Universality in Culture [w:] For Love of Country? Debating the Limits of Patriotism. Martha C. Nussbaum with Respondents, red. J. Cohen, Beacon Press, Boston.

Centrum Sztuki Współczesnej Zamek Ujazdowski, wizyówka WWW, http:/ /www.csw.art.pl/ index.php?action=aktualnosci\&s2=1\&id=1529\&lang= [dostęp:3 lipca 2017].

Chakrabarty Dipesh (2000), Provincializing Europe: Postcolonial Thought and Historical Difference, Princeon UP, Princeton.

Constructing a Sociology of Translation (2007), red. M. Wolf, A. Fukari, John Benjamins, Amsterdam-Philadelphia.

Cronin Michael (2003), Translation and Globalisation, Routledge, London-New York.

Devika Jayakumari (2008), Being “in-Translation” in a Post-Colony. Translating Feminism in Kerala State, India, "Translation Studies" 1:2.

Dilek Dizdar (2009), Translational Transitions: "Translation Proper" and Translation Studies in the Humanities, "Translation Studies" 2:1.

Friel Brian (2000), Translations, Faber, London.

Geertz Clifford (1973), The Interpretation of Cultures, Basic Books, New York.

Gierowski Piotr (2013), Struktury historii. O czeskim projekcie dziejów literatury na tle recepcji praskiego strukturalizmu w Polsce, Wydawnictwo UJ, Kraków. 
Glowacka Dorota (2014), Świadectwa holokaustu a etyka przekładu, „Przekładaniec. A Journal of Translation Studies", 29.

Heaney Seamus (1999), Introduction [w:] Beowulf: A New Translation, ed. S. Heaney, Farrar, Strauss and Giroux, New York.

Hermans Theo (1985), Translation Studies and the New Paradigm [w:] Manipulation of Literature, red. T. Hermans, St. Martin Press, New York.

- (2015), Narada jezylków, red. M. Heydel i K. Szymańska. Wydawnictwo UJ, Kraków.

Heydel Magda (2010), Zwrot kulturowy w badaniach nad przeketadem, „Teksty Drugie”, nr 6.

- (2013), Gorliwość ttumacza. Przektad poetycki w twórczości Czestawa Miłosza, Wydawnictwo UJ, Kraków.

Hoffman Eva (1990), Lost in Translation: A Life in a New Language, Penguin, London.

Holmes James (2007), The Name and Nature of Translation Studies [w:] Translation Studies Reader, red. L. Venuti, wyd. 2, Routledge, New York-London.

Jakobson Roman (2009), O jezylkoznawczych aspektach przekładu, przeł. L. Pszczołowska [w:] Wspótczesne teorie przekładu. Antologia, red. P. Bukowski, M. Heydel, Znak, Kraków.

Kuhiwczak Piotr (2011), How do we Read the Holocaust Memoirs? [w:] Tradition, Translation, Trauma: The Classic and the Modern, red. J. Parker, T. Mathews, Oxford UP, Oxford.

Lefèvere André (1992a), Translation/History/Culture. A Sourcebook, Routledge, London-New York.

- (1992b), Translation, Rewriting and the Manipulation of Literary Fame, Routledge, LondonNew York.

Łukasiewicz Małgorzata (2017), Pięć rasy o przekłładzie, Karakter, Kraków.

Nida Eugene A. (1959), Principles of Translation as Exemplified by Bible Translating [w:] On Translation, red. R. Brower, Mass: Harvard UP, Cambridge.

Pym Anthony (1998), A Method in Translation History, St. Jerome, Manchester.

- (2010), Exploring Translation Theories, Routledge, London-New York.

Ricoeur Paul (2006), On Translation, przel. E. Bennan, Routledge, London-New York.

Simon Sherry (2006), Translating Montreal. Episodes in the life of a divided city, McGill-Queen's UP, Montreal.

Slavs and Tatars, https://www.slavsandtatars.com [dostęp: 10 lutego 2017].

Slavs and Tatars, usta usta, http://www.csw.art.pl/index.php?action=aktualnosci\&s2=1\&i$\mathrm{d}=1529$ \&lang $=$ [dostęp: 10 lutego 2017].

Snell-Hornby Mary (2006), The Turns in Translation Studies. New Paradigms or Shifting View Points?, John Benjmins, Amsterdam-Philadelphia.

Spivak Gayatri Chakravorty (2009), Polityka przekładu [w:] Wspótczesne teorie przekłtadu. Antologia, red. P. Bukowski, M. Heydel, Znak, Kraków.

Steiner George (2000), Po wię̇y Babel. Problemy jezylka i przekłładu, przekład O. i W. Kubińscy, Universitas, Kraków.

- (2004), Transation as 'conditio Humana' [w:] Uebersetzung — Translation — Traduction. An International Handbook of Translation Studies, Walter de Gruyter, Berlin.

Tobis Andrzej (2014), A-Z stownik ilustrowany jezyka niemieckiego i polskiego | A-Z Bildwörterbuch Deutsch und Polnisch, Fundacja Bęc Zmiana, Warszawa.

Toury Gideon (1995), Descriptive Translation Studies and Beyond, John Benjamins, AmsterdamPhiladephia. 
Trivedi Harish (2012), Translating Culture vs. Cultural Translation, http://www.uiowa.edu/ iwp/ 91st/91st_Archive/vol4_n1/pdfs/trivedi.pdf [dostęp: 3 lipca 2012].

Tryuk Małgorzata (2011), 'You say nothing; I will interpret': Interpreting in the Auschwitz-Birkenau Concentration Camp [w:] Translation and Opposition, eds D. Asimakoulas, M. Rogers, Multilingual Matters, Clevendon.

Tymoczko Maria (2007), Enlarging Translation, Empowering Translators, St. Jerome, Manchester. Venuti Lawrence (1995), The Translator's Invisibility. A History of Translation, Routledge, London-New York.

- (2009), Przekład, wspólnota, utopia, przeł. M. Heydel [w:] Wspótczesne teorie prąekładu. Antologia, red. P. Bukowski, M. Heydel, Znak, Kraków.

- (2013), Translation Changes Everything. Theory and Practice, Routledge, London-New York.

Vieira Else Ribeiro Pires (1999), Liberating Calibans: Reading of Antropofagia and Haraldo de Campos' Poetics of Transcreation [w:] Post-colonial Translation. Theory and Practice, eds S. Bassnett, H. Trivediego, Routledge, London-New York.

Vinay Jean-Paul, Jean Darbelnet (1957), Stylistique comparée du français et de l'anglais, Didier, Paris. 